\title{
Machining Parametric Optimization of Wire Electrical Discharge Machining in cutting Nimonic-75 using Response Surface Methodology
}

\author{
G R Sanjay Krishna ${ }^{1}$, M. Sreenivas Rao ${ }^{2}$, N.Tamiloli ${ }^{1}$ \\ ${ }^{1}$ Department of Mechanical Engineering, KLEF, Vaddeswaram, Andhra Pradesh, -522502 \\ Emails: grskrishna@gmail.com \\ ${ }^{2}$ Department of Mechanical Engineering, JNTUH-Hyderabad
}

\begin{abstract}
Wire electrical release machining is an option competing and current non-conventional machining measure. This paper focuses on the trial examination of Wire Electrical Discharge Machining (WEDM) while cutting Nimonic 75 material. Pulse on time, Pulse off time, servo voltage, and wire feed are considered as cycle boundaries; and surface roughness (SR) and material removal rate (MRR) is taken as output response. In improving the machining yield and surface trademark, surface roughness and material removal rate assume a noteworthy job individually. Thus, it is required to break down these replication boundaries in connection with the information boundaries. The goal of this work is to get least surface roughness and most extreme materials removal rate and to distinguish principal input boundaries that impact these replication boundaries by factual displaying. The exploratory plan has been cultivated by the L29 orthogonal array with three distinct bores of each machining boundary and trials are performed. In this research work, assessment of optically peddled information has been done by embracing the Taguchi method, analysis of variance, and response surface methodology. It has been discovered that the pulse off time is the most significant boundary in surface roughness and pulse on time is the most foremost boundary in material removal rate.
\end{abstract}

Keywords: Time, voltage, Nimonic, feed, etc.

\section{INTRODUCTION}

Machining processes are vital in today's industries. The advanced raw material machinery affects products that are difficult to machine using the traditional machining process. Therefore traditional machining process has gained prominence, overcoming the shortcomings of conventional machining processes. The non-conventional machining method has advantages like precision, quality, accuracy, capability, cut high-strength materials, and to perform complex cutting on workpieces having complex structures.

The WEDM is one of the most widely used non-conventional manufacturing processes used for producing difficult cutouts through difficult to machine metals without using high-cost grinding or classy forms tools. It is well-thought-out as a unique adaption of the conventional EDM process. During cutting. As the wire doesn't touch the workpiece, there is no cutting pressure or mechanical stress imparted on the workpiece compared to milling cutters and the grinding wheels. As metal removal is based on multipart thermal and chemical phenomena; to understand its properties on the machined components, a search has been made in this project.

WEDM is broadly utilized because it tends to be completely mechanized and is adaptable in making complex geometrical shapes in a single arrangement, although the essential rule has not changed in WEDM, the electrode is tinny wire. The wire 
G R Sanjay Krishna et al., International Journal of Emerging Trends in Engineering Research, 8(10), October 2020, 7377 - 7384

feed from the reel, utilizing sparkles of electric vitality to logically dissolve an electrically conductive workpiece along the way controlled by the general movement of the machine pivot. WEDM utilizes metal, copper, zinc covered brass wire, extending from 0.05 to $0.25 \mathrm{~mm}$ in distance across. At the point when the voltage arrives at the right level, a sparkle bounces the hole and melts a little bit of the workpiece. The wire is encompassed by de-ionized water. The de-ionized water releases electric starts and flushes away little particles from the hole. WEDM is precise and no burrs are produced.

Chandrasekhar et al [1] led to investigates SS317 by utilizing the WEDM machine. output reactions to be categorical as material abstraction rate and surface roughness were estimated. It was optically discerned that pulse on time is the most immensely colossal factor that impacts all replications, were as MRR and SR expanded greatly with the optimal parameters. Dhruv H. Gajjar et al [2] performed on E31 steel by utilizing molybdenum on WEDM. A study on optimization of MRR and SR and Kerf width utilizing grey cognation examination was made in this present investigation. it was optically discerned that the expansion on the pulse on-time engenders crater with broader and trademark which establishes increment of surface unpleasantness. Mohapatra et al [3] demystified about multi-objective optimization utilizing WEDM on Inconel 718. process parameter to be a concrete pulse on time, pulse off time, and wire tension, were taken as machining parameters it was visually perceived that pulse on time was visually perceived as the most paramount factor in affecting the reactions concretely MRR and Kerf Width. Mandeep et al [4] enhanced the material abstraction rate by utilizing Taguchi Technique while machining Inconel X750. Investigation of variance was done to determine the caliber of the paramount of machining parameters on the metal abstraction rate. it was optically discerned that pulse on time, pulse off time, spark gap voltage and peak current are visually perceived as astronomically immense components.

Amitesh et al [5] researched material abstraction rate, SR, and wire wear ratio. Taguchi's plan of experiments was utilized for machining the Nimonic $80 \mathrm{~A}$ workpiece. to contemplate the microstructure of the machined tests, a scanning electron microscope is utilized. it was optically discerned that deeper and more astronomically immense apertures on the outside of the workpiece are shaped because of higher discharge energy. Vivek et al [6] consummated analyses on Inconel 718 material by utilizing replication surface methodology. zinc covered brass wire was utilized as the cathode material. it was comprehended that among the considered process parameters pulse on time is the most consequential parameters affecting the process parameters.

Priyaranjansharma et al [7] led probe Inconel 706 which is as of tardy engendered alloy utilized in aerospace applications. By utilizing ANOVA, MRR, and SR has been streamlined. Microstructure examination metallurgical changes and microhardness estimations of the machine surface has been performed it was visually perceived that pulse on time on schedule and pulse off time has more effect on performed characteristics. Azam et al [8] in their experiment learned about the amendment of process parameters by varying machining parameters. Impacts of cutting parameters of WEDM on material abstraction rate of Titanium alloy postulated that MRR increments with increment in pulse duration and servo voltage. It is supplemental optically discerned that the impact of pulse duration on discharge current prompts ascend in MRR. Karim et al [9] adopted the grey relational analysis technique for upgrading machining parameters to be categorical on the pulse on time, pulse off time, flushing pressure, and wire tension. it was discovered that discharge current was the most impact parameter which impacts the output replication. Boujelbene et al [10] examining about sundry WEDM parameters output reaction while machining high composite steel. molybdenum wire is utilized in the examination by utilizing di-ionized dihydrogen monoxide was the collect. it was visually perceived that by incrementing servo voltage value the surface roughness increments. 
G R Sanjay Krishna et al., International Journal of Emerging Trends in Engineering Research, 8(10), October 2020, 7377 - 7384

Pradeep et al [11] endeavored to optimize the machining conditions by utilizing the Taguchi technique. to inhibit the surface Roughness. Pulse on time, pulse off time, peak current were utilized to the required machining process. It was optically discerned that by expanding the pulse on-time surface roughness increases. It was adscititiously optically discerned that pulse off time was the critical factor pursued by pulse on time.

Germain et al [12] portrayed that nickel-based alloy were hard to machine since they keep up their mechanical and physical properties even at raised temperatures. Thus, ordinary machining $(\mathrm{CM})$ of these materials is difficult and inadequate on the grounds that moderate machining speeds were liked. The yield reactions estimated by Kuppan et al. [13] were the MRR. The numerical models were inferred for this reaction utilizing the RSM. Prihandana et al. [14] examined the impact of molybdenum disulfide (MoS2) powder suspended in the dielectric liquid on the execution in miniature EDM of Inconel 718. Nourishment and Bhattacharyya [15] acquired ideal boundary setting during EDM and decided their impact on machining execution. They created numerical models by utilizing the gauss disposal strategy.

Baburaja et al [16] studied the effect of various input parameters on aluminum and Hastelloy while machining by WEDM using Taguchi Approach. Rao K.S et al[17] studied the effect of various input parameters on surface roughness on turning of Niobium alloy C-103 by using RSM. Ram Prasad et al [18] used the Taguchi Method for multi-response Optimization of machining parameters for Wire Electrical Discharge Machining of Lead-Induced Ti-6Al-4V Alloy. Many of the researchers are carried out Inconel alloy and finding the different optimal levels is studied [18-22]. Based on the design of experiments, Taguchi, response surface methodology, and multi response optimization technique are studied the WEDM with different workpiece materials [23-25]. Khudov et al [26] studied the optimizing discrete search and detection of observation objects. Wicaksono et al [27] analyzed the experiment, MGSPSO could increase Grid Search and Particle
Swarm Optimization (PSO) accuracy rate by about $3 \%$. MGSPSO also could decrease Grid Search recognition time. In the present work, the mathematical models were developed, and also verification tests for the developed models were carried out, to obtain the optimal settings of process parameters to achieve optimum surface roughness on the specimen made of Nimonic -75 processed by the WEDM process. This study also investigates the effects of process parameters on surface roughness and material removal rate of the machined surface.

\section{MATERIALS AND METHODS}

The experiments were conducted a CNC wire EDM (ULTRA CUT -843)as shown in figure 1 . Brass wire of $0.25 \mathrm{~mm}$ diameter was used as the cutting tool wire material and Nimonic-75 is a workpiece material $(70 \mathrm{~mm} \times 50 \mathrm{~mm} \times 10 \mathrm{~mm})$ having a thickness of $10 \mathrm{~mm}$. The deionized water was used as dielectric and its temperature was kept at $20^{\circ} \mathrm{C}$. The chemical composition of the workpiece material is shown in Table 1.

Table 1. Chemical composition of workpiece material (\%)

\begin{tabular}{l|l|l|l|l|l|l|l}
\hline $\mathrm{C}$ & $\mathrm{si}$ & $\mathrm{Mn}$ & $\mathrm{Cr}$ & $\mathrm{Fe}$ & $\mathrm{Cu}$ & $\mathrm{Ti}$ & $\mathrm{Ni}$ \\
\hline 0.0 & 0. & 0.2 & 20. & 3. & 0.0 & 0.2 & 75. \\
97 & 193 & 95 & 15 & 18 & 55 & 25 & 28
\end{tabular}

The machining parameters are servo voltage, pulse-on time, pulse-off time, and wire feed rates are shown in table 2 . The output effects on surface roughness and material removal rate are shown in table 3. The ranges of input parameters were selected based on the literature survey. The surface roughness was measured with help of a talysurf roughness tester. The material removal rate also finds out from the high precision weighing machine used the below equation no 1 .

(Initial weight-Final weight) / ( $\rho$ x time)

$$
\rho \text {-Density of material }-8.37 \mathrm{grm} / \mathrm{cm}^{3}
$$

The experimental setup is shown in Figure 1. 
G R Sanjay Krishna et al., International Journal of Emerging Trends in Engineering Research, 8(10), October 2020, 7377 - 7384

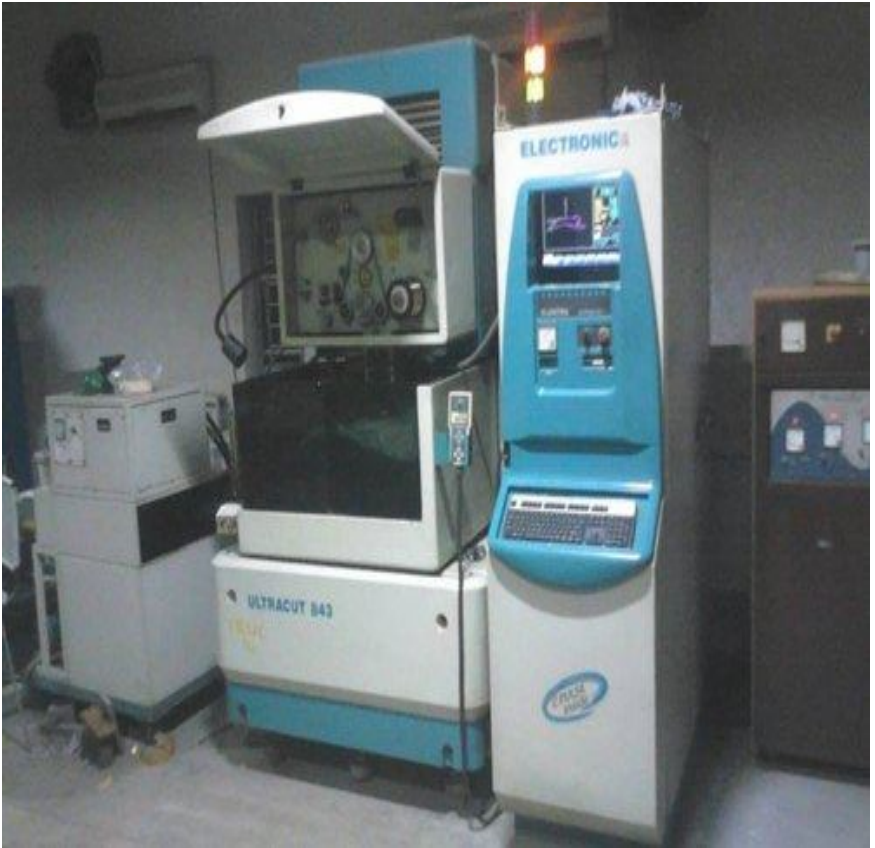

Figure -1 Experimental setup

Table 2 - Machining parameters

\begin{tabular}{l|l|r|r|c}
\hline $\begin{array}{l}\text { Input } \\
\text { parameters }\end{array}$ & Units & Level 1 & Level 2 & Level 3 \\
\hline Pulse on time & $\mu s$ & 107 & 109 & 111 \\
\hline Pulse off time & $\mu$ is & 60 & 58 & 56 \\
\hline Servo voltage & $v$ & 15 & 20 & 25 \\
\hline Wire feed & $\mathrm{m} / \mathrm{min}$ & 1 & 2 & 3 \\
\hline
\end{tabular}

Table 3- Machining parameters and process performance.

\begin{tabular}{c|c|c|c|c|c|c}
\hline $\begin{array}{c}\text { Exp } \\
\text { No }\end{array}$ & $\begin{array}{c}\text { Pulse } \\
\text { on } \\
\text { time } \\
(\mu \mathrm{s})\end{array}$ & $\begin{array}{c}\text { Pulse } \\
\text { off } \\
\text { time } \\
(\mu \mathrm{s})\end{array}$ & $\begin{array}{c}\text { Servo } \\
\text { voltage } \\
(\mathrm{v})\end{array}$ & $\begin{array}{l}\text { Wire } \\
\text { feed } \\
(\mathrm{m} / \mathrm{min})\end{array}$ & $\begin{array}{c}\text { SR } \\
(\mu \mathrm{m})\end{array}$ & $\begin{array}{c}\text { MRR } \\
\left(\mathrm{mm}^{3} /\right. \\
\mathrm{min})\end{array}$ \\
\hline 1 & 109 & 58 & 20 & 2 & 1.164 & 91.677 \\
\hline 2 & 111 & 56 & 20 & 2 & 1.484 & 94.639 \\
\hline 3 & 111 & 58 & 15 & 2 & 1.496 & 94.651 \\
\hline 4 & 109 & 58 & 25 & 1 & 1.054 & 92.569 \\
\hline 5 & 109 & 56 & 20 & 3 & 1.313 & 92.773 \\
\hline 6 & 111 & 58 & 20 & 1 & 1.355 & 94.543 \\
\hline 7 & 109 & 56 & 25 & 2 & 1.182 & 92.665 \\
\hline 8 & 109 & 58 & 20 & 2 & 1.184 & 92.677 \\
\hline 9 & 109 & 60 & 15 & 2 & 1.186 & 92.688 \\
\hline 10 & 107 & 58 & 25 & 2 & 0.883 & 90.703 \\
\hline 11 & 109 & 60 & 20 & 3 & 1.103 & 92.580 \\
\hline 12 & 109 & 58 & 20 & 2 & 1.184 & 92.677 \\
\hline 13 & 107 & 58 & 20 & 3 & 1.013 & 90.811 \\
\hline 14 & 109 & 58 & 20 & 2 & 1.184 & 92.677 \\
\hline 15 & 111 & 58 & 20 & 3 & 1.402 & 94.443 \\
\hline 16 & 111 & 60 & 20 & 2 & 1.274 & 94.446 \\
\hline 17 & 109 & 58 & 20 & 2 & 1.184 & 92.677 \\
\hline
\end{tabular}

\begin{tabular}{l|l|l|l|l|l|l}
\hline 18 & 109 & 58 & 15 & 3 & 1.315 & 92.885 \\
\hline 19 & 109 & 60 & 20 & 1 & 1.056 & 92.580 \\
\hline 20 & 107 & 58 & 20 & 1 & 0.967 & 90.811 \\
\hline 21 & 109 & 56 & 20 & 1 & 1.266 & 92.773 \\
\hline 22 & 107 & 58 & 15 & 2 & 1.097 & 90.919 \\
\hline 23 & 109 & 58 & 15 & 1 & 1.268 & 92.785 \\
\hline 24 & 109 & 60 & 25 & 2 & 0.972 & 92.472 \\
\hline 25 & 109 & 58 & 25 & 3 & 1.100 & 92.569 \\
\hline 26 & 107 & 60 & 20 & 2 & 0.885 & 90.714 \\
\hline 27 & 109 & 56 & 15 & 2 & 1.297 & 92.881 \\
\hline 28 & 107 & 56 & 20 & 2 & 1.095 & 90.907 \\
\hline 29 & 111 & 58 & 25 & 2 & 1.171 & 93.435 \\
\hline
\end{tabular}

\section{RESULTS AND DISCUSSION}

\subsection{Effects of surface roughness}

The experimental data perpetuates to increment surface irregularity decreases because of the on-time and off-time increases. But the roughness of the material is low once on time is $5 \mu$ s and the Discharge current is $2000 \mathrm{~A}$. The mathematical model prevised values and ergo the experimental values of SR square measure compared with one another and diagrammatically shown within the Fig. 2. It's studied that the foremost influencing parameters square measure pulse on, pulse off time to most SR, and ergo the minor influencing parameters square measure discharge current and servo speed to supply minimum SR. The optimal level of surface roughness is A3-B1-C1-D3 shown in figure 3.

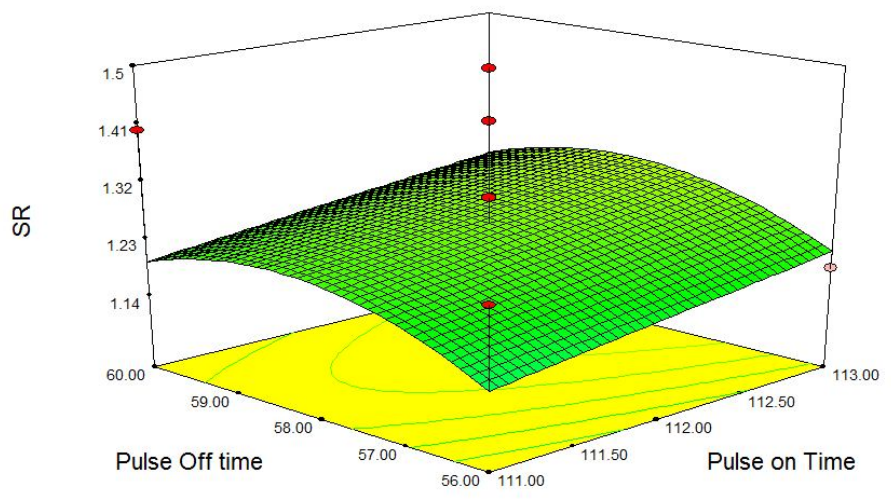

Figure 2. Surface roughness for SR pulse on time and pulse off time 


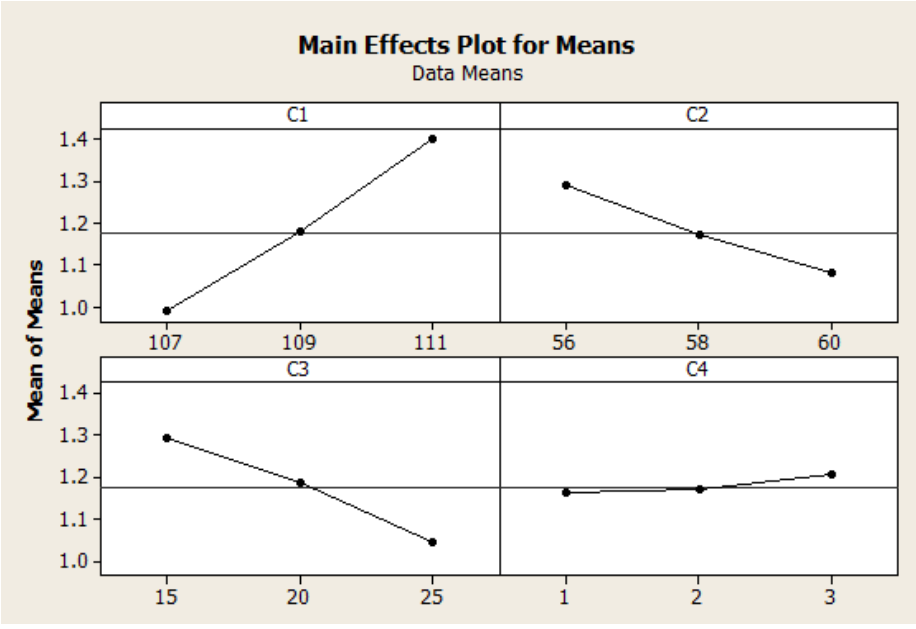

Figure 3. The optimal level of surface roughness

\subsection{Effects of process parameters on MRR}

Table. 3 that expounds that the MRR inclines to elongate to incrementing level of on-time and speed rate then culminates up in a high rate of wire EDM which ends within the high material rate. .The mathematical model prognosticated values and withal the experimental values of MRR are compared with one another and diagrammatically shown within the Fig. 4. It's studied that the key Influencing parameters are pulse on, servo speed to most MRR, and additionally the minor influencing parameters are discharge current and off-time parameters influencing minimum abstraction of material. After cutting two quality objectives were culled, including abstraction rate of material and surface irregularity. The review of the model is incredibly abundant indispensable once the analysis of cognizance. The optimal level of material removal rate is A3-B1-C1-D1 shown in figure 5.

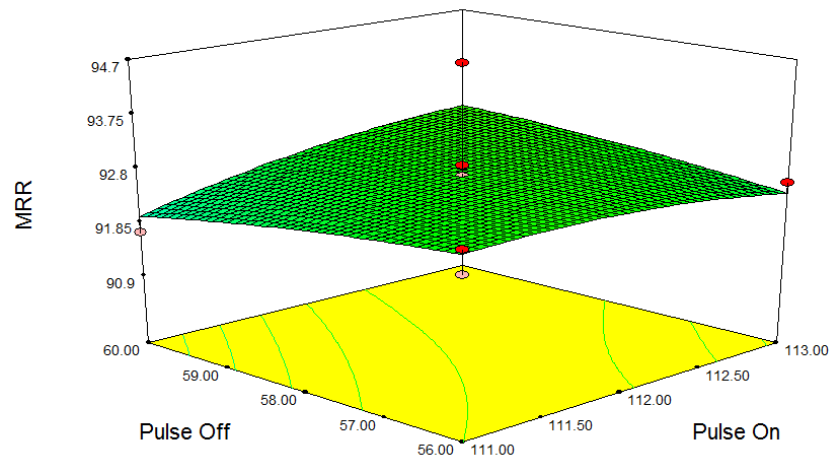

Figure 4. Surface response for MRR versus Pulse on and pulse off time

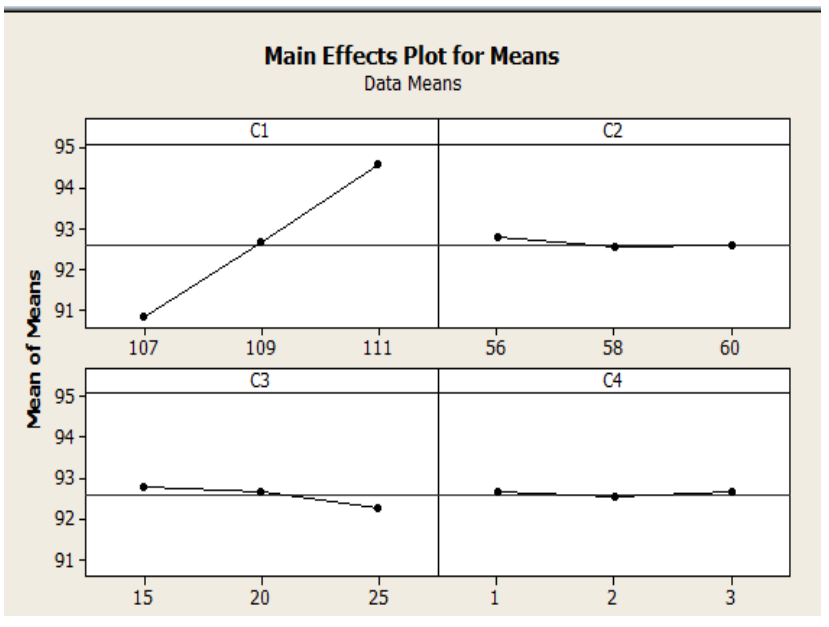

Figure 5. An optimal level of Material removal rate

\subsection{Analysis of Variance and RSM}

Analysis of variances has been performed and the P-value for every model in, mentioned tables is a more diminutive amount than 0.05 , denoting that for a confidence level of $97.4 \%$, the models are statistically vital and terms within the model have the many impacts on the replications. The final replication equation for sundry performance measures like SR and MRR are given as follows equations 2 and 3 . The regression statics variance of surface roughness, regression statistics, and material removal rate is shown in tables 4,5 and 6 .

$\mathrm{SR}=1.09+0.086 * \mathrm{~A}-0.045 * \mathrm{~B}-0.050 * \mathrm{C}+0.011 *$

$\mathrm{D}+4.047 \mathrm{E}-003 * \mathrm{~A} * \mathrm{~B}-8.209 \mathrm{E}-003 * \mathrm{~A} * \mathrm{C}-8.891 \mathrm{E}-004 * \mathrm{~A} * \mathrm{D}-0$. $013 * \mathrm{~B} * \mathrm{C}+4.753 \mathrm{E}-004 * \mathrm{~B} * \mathrm{D}+4.848 \mathrm{E}-004 * \mathrm{C} * \mathrm{D}-4.436 \mathrm{E}-003 *$ $\mathrm{A}^{2}-2.041 \mathrm{E}-003 * \mathrm{~B}^{2}-7.230 \mathrm{E}-003 * \mathrm{C}^{2}+4.402 \mathrm{E}-003 *$

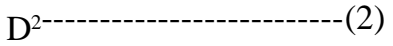

$\mathrm{MRR}=92.73+0.14 * \mathrm{~A}-0.06 * \mathrm{~B}+0.12 * \mathrm{C}+0.028 * \mathrm{D}+0.30 * \mathrm{~A} *$ $\mathrm{B}+0.45 * \mathrm{~A} * \mathrm{C}-0.21 * \mathrm{~A} * \mathrm{D}+0.86 * \mathrm{~B} * \mathrm{C}+0.91 * \mathrm{~B} *$ $\mathrm{D}-0.93 * \mathrm{C} * \mathrm{D}-0.17 * \mathrm{~A}^{2}-0.083 * \mathrm{~B}^{2}+0.30 * \mathrm{C}^{2}-0.36 *$ $\mathrm{D}^{2------------------(3)}$

Table 4. ANOVA for surface roughness

\begin{tabular}{l|l|l|l|l|l|l}
\hline Source & SS & Df & MS & $\begin{array}{l}\text { F } \\
\text { Value }\end{array}$ & $\begin{array}{l}\text { P value } \\
>\text { F }\end{array}$ & \\
\hline Model & 0.147 & 14 & 0.0104 & 76.73 & $<0.0001$ & S \\
\hline A-A & 0.089 & 1 & 0.0893 & 654.29 & $<0.0001$ & \\
\hline B-B & 0.024 & 1 & 0.0242 & 177.58 & $<0.0001$ & \\
\hline C-C & 0.030 & 1 & 0.030 & 219.89 & $<0.0001$ & \\
\hline D-D & 0.001 & 1 & 0.001 & 10.09 & 0.01 & \\
\hline AB & 0.000 & 1 & $6.5 \mathrm{E}-05$ & 0.48 & 0.50 & \\
\hline AC & 0.000 & 1 & 0.00026 & 1.97 & 0.18 & \\
\hline AD & 0.000 & 1 & $3.16 \mathrm{E}-6$ & 0.02 & 0.88 & \\
\hline
\end{tabular}


G R Sanjay Krishna et al., International Journal of Emerging Trends in Engineering Research, 8(10), October 2020, 7377 - 7384

\begin{tabular}{l|l|l|l|l|l|l}
\hline $\mathrm{BC}$ & 0.001 & 1 & 0.0006 & 4.93 & 0.04 & \\
\hline $\mathrm{BD}$ & 0.000 & 1 & $9.04 \mathrm{E}-7$ & 0.01 & 0.94 & \\
\hline $\mathrm{CD}$ & 0.000 & 1 & $9.40 \mathrm{E}-7$ & 0.01 & 0.94 & \\
\hline $\mathrm{A}^{\wedge} 2$ & 0.000 & 1 & 0.0001 & 0.93 & 0.35 & \\
\hline $\mathrm{B}^{\wedge} 2$ & 0.000 & 1 & $2.7 \mathrm{E}-05$ & 0.20 & 0.66 & \\
\hline $\mathrm{C}^{\wedge} 2$ & 0.000 & 1 & 0.00033 & 2.48 & 0.14 & \\
\hline $\mathrm{D}^{\wedge} 2$ & 0.000 & 1 & 0.0001 & 0.92 & 0.35 & \\
\hline Residual & 0.002 & 14 & 0.0001 & & & \\
\hline $\begin{array}{l}\text { Lack of } \\
\text { Fit }\end{array}$ & 0.002 & 10 & 0.0001 & 10.83 & 0.02 & $\mathrm{~S}$ \\
\hline $\begin{array}{l}\text { Pure } \\
\text { Error }\end{array}$ & 0.000 & 4 & $1.70 \mathrm{E}-5$ & & & \\
\hline $\begin{array}{l}\text { Cor } \\
\text { Total }\end{array}$ & 0.149 & 28 & & & & \\
\hline \multicolumn{1}{c}{$\mathrm{SS}-\mathrm{S}$} & & & & & \\
\hline
\end{tabular}

\begin{tabular}{c|l|l|l|l|l|l}
\hline Fit & & & & & & \\
\hline Pure & 7.02 & 4 & 1.755 & & & \\
Error & & & & & & \\
\hline $\begin{array}{c}\text { Cor } \\
\text { Total }\end{array}$ & 40.05 & 28 & & & & \\
\hline
\end{tabular}

SS- Sum of the square, Df- Degree of freedom, MS- Mean square, NS- Not Significant.

\section{CONFIRMATION TEST}

The purpose of the confirmation experiment is to validate the conclusions obtained from the experiment. In this study, a confirmation experiment has been conducted using the optimal parameter of significance. The optimal settings, the response values from the experiments are $0.756 \mathrm{Ra}(\mathrm{SR})$ and MRR 94.7476 $\mathrm{mm} 3 / \mathrm{min}$. The confirmation results are shown in Table 7 .

Table 5. Regression Statistics

\begin{tabular}{|c|c|}
\hline \multicolumn{2}{|c|}{ Regression Statistics } \\
\hline Multiple R & 0.987 \\
\hline R Square & 0.974 \\
\hline Adjusted R Square & 0.970 \\
\hline Standard Error & 0.026974 \\
\hline Observations & 29 \\
\hline
\end{tabular}

Table 6. ANOVA for material removal rate

\begin{tabular}{c|l|l|l|l|l|l}
\hline Source & SS & df & MS & $\begin{array}{l}\text { F } \\
\text { Value }\end{array}$ & P-value & \\
\hline Model & 13.47 & 14 & 0.962 & 0.507 & 0.892 & NS \\
\hline A-A & 0.23 & 1 & 0.234 & 0.123 & 0.731 & \\
\hline B-B & 0.05 & 1 & 0.051 & 0.027 & 0.872 & \\
\hline C-C & 0.18 & 1 & 0.178 & 0.094 & 0.764 & \\
\hline D-D & 0.01 & 1 & 0.009 & 0.005 & 0.945 & \\
\hline AB & 0.37 & 1 & 0.370 & 0.195 & 0.666 & \\
\hline AC & 0.80 & 1 & 0.803 & 0.423 & 0.526 & \\
\hline AD & 0.18 & 1 & 0.183 & 0.096 & 0.761 & \\
\hline BC & 2.95 & 1 & 2.950 & 1.554 & 0.233 & \\
\hline BD & 3.30 & 1 & 3.304 & 1.740 & 0.208 & \\
\hline CD & 3.46 & 1 & 3.461 & 1.823 & 0.198 & \\
\hline $\mathrm{A}^{\wedge} 2$ & 0.19 & 1 & 0.188 & 0.099 & 0.758 & \\
\hline $\mathrm{B}^{\wedge} 2$ & 0.04 & 1 & 0.044 & 0.023 & 0.881 & \\
\hline $\mathrm{C}^{\wedge} 2$ & 0.59 & 1 & 0.588 & 0.310 & 0.587 & \\
\hline $\mathrm{D}^{\wedge} 2$ & 0.82 & 1 & 0.818 & 0.431 & 0.522 & \\
\hline Residual & 26.58 & 14 & 1.898 & & & \\
\hline Lack of & 19.56 & 10 & 1.956 & 1.115 & 0.499 & NS \\
\hline & & & & & & \\
\hline
\end{tabular}

Table 7. Confirmation Test

\begin{tabular}{|c|c|c|c|}
\hline Parameters & Initial level & Optimal level & $\begin{array}{l}\text { Improvement } \\
(\%)\end{array}$ \\
\hline SR & $\begin{array}{l}\text { A1-B1-C3-D2 } \\
(\mu \mathrm{m})\end{array}$ & $\begin{array}{l}\text { A1-B1-C3-D1 } \\
(\mu \mathrm{m})\end{array}$ & \multirow[b]{2}{*}{2.702} \\
\hline & 0.777 & 0.756 & \\
\hline MRR & $\begin{array}{l}\text { A1-B1-C3-D2 } \\
\left(\mathrm{mm}^{3} / \mathrm{min}\right)\end{array}$ & $\begin{array}{l}\text { A3-B1-C3 } \\
\left(\mathrm{mm}^{3} / \mathrm{min}\right)\end{array}$ & \multirow[b]{2}{*}{4.371} \\
\hline & 90.606 & 94.7476 & \\
\hline
\end{tabular}

\section{CONCLUSIONS}

In this work, an endeavor was made to study the effects of pulse-on time, pulse-off time, and servo voltage and wire victual rate on surface roughness and materials abstraction rate in WEDM of Nimonic-75. Input process parameters have been found to play a consequential role in the minimization of pulse on time. ANOVA results show that pulse off time and wire victual rate are highly consequential parameters in surface roughness. Pulse-on time and pulse off time more consequential effect on material abstraction rate. An optimized value of surface roughness is 107 pulses-on time, pulse off 60 , servo volt 25 , and wire victual rate is 1 . Optimized values of material abstraction rate are pulse-on time is 111 , pulse off time is 56 , servo volt 15 , and wire victual rate is 3 . The conformation results have shown amendment of surface roughness $14.57 \%$ and Material abstraction rate is $4.25 \%$ is amended. 
G R Sanjay Krishna et al., International Journal of Emerging Trends in Engineering Research, 8(10), October 2020, 7377 - 7384

\section{REFERENCES}

1. Y. Chandra Sekhar Reddy, T. Pratheep Reddy, 2017. Optimization of WEDM Process Parameters on SS 317 using Grey relational analysis, International Research Journal of Engineering and Technology, 2395-0072.

2. Dhruv H. Gajjar, Jayesh V. Desai, 2015. Optimization of MRR, Surface Roughness, and KERF Width in WEDM using Molybdenum wire, An International Journal for Research in Education. 4, 2.

3. K.D. Mohapatra, S.K. Sahoo, 2017. A multi-objective optimization of gear cutting in WEDM of Inconel 718 using the TOPSIS method, DOI:10.5267/j.dsl.2017.6.002.

4. Mandeep Kumar, Hari Singh 2016. Optimization of process parameters of WEDM for Material Removal Rate using the Taguchi technique, Indian Journal Engineering, and Material Sciences, 23, 223-320.

5. Amitesh Goswami, Jatinder Kumar, 2017. Investigation of surface integrity, material removal rate and wire wear ratio for WEDM of Nimonic $80 \mathrm{~A}$ alloy using GRA and Taguchi method", Engineering Science and Technology, an International Journal,17,4, DOI: 10.1016/ j.jestch.2014.05.002.

6. Vivek Aggarwal, Sehijpal Singh Khangura Parametric modeling and optimization for WEDM of Inconel 718 using response surface methodology, Int J Adv. ManufTechnol,

DOI:10.1007/s00170-015-6797-8.

7. Priyaranjan Sharma, D. Chakradhar, 2017. Analysis and Optimization of WEDM performance characteristics of Inconel 706 for Aerospace applications, Springer, DOI:10.1007 /s12633-017-9549-6.

8. N. Azam, M. Afendi, 2016, Effect of WEDM cutting parameters on Material Removal Rate of Titanium Alloy, AIP conference proceedings 1756, 060001; DOI: 10.1063/1.4958775, 2016.
9. Md. Karim Baig, N. Venkaiah, "Parametric optimization of WEDM for Hastelloy C276, using GRA method", International Journal of Engineering Development of Research,

10. M. Boujelbene, S. Ezzdini, 2017. Investigation on the surface roughness of high steel material after WEDM process, International journal of advanced and applied sciences, 4(6), 130-136.

11. Pradeep Kumar Karsh, Hari Singh,2016. Optimization of process parameters for Surface roughness of Inconel 625 in WEDM by using Taguchi method", IOSR Journal of Mechanical and Civil Engineering and Technology (IRJET), 3,3.

12. G. Germain, J.L. Lebrun, T. Braham-Bouchnak, D. Bellett, S. Auger, 2008, Laser-assisted machining of Inconel 718 with carbide and ceramic inserts, Int. J.Mater. Form. 523-526.

13. P. Kuppan, A. Rajadurai, S. Narayanan, 2008. Influence of EDM process parameters in deep hole drilling of Inconel 718, Int. J. Adv. Manuf. Technol. $38,74-84$.

14. G.S. Prihandana, T. Sriani, M. Mahardika, M. Hamdi, N. Miki, Y.S. Wong, K. Mitsui, 2014, Application of powder suspended in dielectric fluid for fine finish micro-EDM of Inconel 718, Int. J. Adv. Manuf. Technol. 75, 599-613.

15. A. Manna, B. Bhattacharyya, 2006. Taguchi and Gauss elimination method: A dual Response approach for parametric optimization of CNC wire cut EDM of Al/SiCMMC, Int. J. Adv. Manuf. Technol. 28, $67-75$.

16. Baburaja K., Subbaiah K.V., Vanaja T., Ramesh N.N. 2017. Resultant Surface Roughness Aluminium and Hastelloy C-276 Using Wire Electro Discharge Machining, Materials Today: Proceedings, 4(2), 1013-1018.

17. Rao K.S., Rao C.S.P., Bose P.S.C., Rao B.B., Ali A., Kishore Kumar K. 2017. Optimization of Machining 
G R Sanjay Krishna et al., International Journal of Emerging Trends in Engineering Research, 8(10), October 2020, 7377 - 7384

Parameters for surface roughness on turning of Niobium alloy C-103 by using RSM', Materials Today: Proceedings,4(2), 2248-2254.

18. Ram Prasad A.V.S., Ramji K., Raghu Kumar B.2018. Study of wire-electrical discharge machining parameters of titanium alloy by using the taguchi method', International Journal of Engineering and Technology(UAE),7(2), 10-12.

19. B.V D., Kodali S.P., Boggarapu N.R. 2019, 'Multi-objective optimization for optimum abrasive water jet machining process parameters of Inconel718 adopting the Taguchi approach', Multidiscipline Modeling in Materials and Structures, 16(2), 306-321.

20. Kumar A., Vivekananda K., Abhishek K. 2019. Experimental Investigation and Optimization of Process Parameter for Inconel 718 Using Wire Electrical Discharge Machining, Journal of Advanced Manufacturing Systems, 18(3), 339-362.

21. Dharmendra B.V., Kodali S.P., Nageswara Rao B. 2019, A simple and reliable Taguchi approach for multi-objective optimization to identify optimal process parameters in nano-powder-mixed electrical discharge machining of INCONEL800 with copper electrode, Heliyon, 5(8).

22. Venkatarao K., Anup Kumar T. 2019. Experimental parametric analysis on performance characteristics in wire electric discharge machining of Inconel 718', Proceedings of the Institution of Mechanical Engineers, Part C: Journal of Mechanical Engineering Science, 233(14), 4836-4849.

23. Suresh A., Diwakar G. 2019. Optimization of process parameters in turning operation of austenitic stainless steel rod using taguchi method and ANOVA, International Journal of Mechanical and Production Engineering Research and Development, 9(3), 379-386.

24. Ram Prasad A.V.S., Ramji K., Kolli M., Vamsi Krishna G. 2019. Multi-Response Optimization of
Machining Process Parameters for Wire Electrical Discharge Machining of Lead-Induced Ti-6Al-4V Alloy Using AHP-TOPSIS Method, Journal of Advanced Manufacturing Systems, 18(2), 213-236.

25. Kumar, A., Vivekananda, K., \& Abhishek, K. 2019. Experimental Investigation and Optimization of Process Parameter for Inconel 718 Using Wire Electrical Discharge Machining (WEDM). Journal of Advanced Manufacturing Systems.

26. Hennadii Khudov, Irina Khizhnyak, Iryna Yuzova, Oleksii Baranik, Galina Semiv, Semen Bondarenko, Olexander Tytarenko, 2020 The Optimization Technique for Joint Discrete Search and Detection of Observation Objects, International Journal of Emerging Trends in Engineering Research, 8(2), 533-538.

27. Aloysius Ari Wicaksono, Antoni Wibowo, 2020, An Optimized SVM Using Multiple Grid Search and Particle Swarm Optimization for Medication Errors Detection, International Journal of Emerging Trends in Engineering Research,8(8), 4056-4060. 